Annales Geophysicae (2003) 21: 1667-1679 C European Geosciences Union 2003

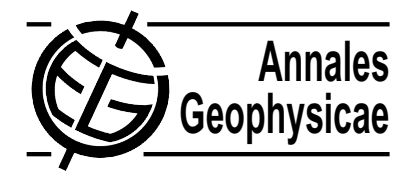

\title{
Wind Speed dependence of Air-Sea Exchange parameters over the Indian Ocean during INDOEX, IFP-99
}

\author{
D. Bala Subrahamanyam and Radhika Ramachandran \\ Space Physics Laboratory, Vikram Sarabhai Space Centre, Thiruvananthapuram, 695 022, Kerala, India
}

Received: 6 June 2002 - Revised: 24 November 2002 - Accepted: 9 February 2003

\begin{abstract}
Air-Sea exchange of momentum, heat and moisture over the oceanic surface plays an important role in understanding several processes spanning various scales of atmospheric and oceanic motions. The present study provides estimates of air-sea exchange parameters along the cruise track of the Intensive Field Phase of Indian Ocean Experiment (INDOEX, IFP-99) conducted on board Oceanic Research Vessel (ORV) Sagar Kanya during 20 January-12 March 1999 for a large region of the Indian Ocean. The study is aimed at acquiring a better understanding of the wind speed dependence of air-sea interaction parameters, such as roughness lengths for wind $\left(z_{0}\right)$, temperature $\left(z_{0 t}\right)$ and humidity $\left(z_{0 q}\right)$, which play a key role in the determination of the air-sea exchange coefficients and interface fluxes across the tropical oceans. The variation of drag coefficient $\left(C_{D}\right)$, sensible heat and water vapor exchange coefficients $\left(C_{H}\right.$ and $C_{E}$ ), are also discussed in relation to the wind speed. An empirical relation is derived between the estimated values of drag coefficients and the observed values of wind speeds for the hitherto data-sparse regions over the tropical Indian Ocean.
\end{abstract}

Key words. Oceanography: physical (air-sea interaction) Meteorology and atmospheric dynamics (ocean-atmosphere interaction) - Oceanography: physical (marine meteorology)

\section{Introduction}

An important component of marine meteorological research is the determination of energy balance components at the oceanic surface through the estimation of air-sea exchange of momentum, heat and water vapor. Given the considerable area covered by the oceans on the Earth, it is of fundamental importance that we adequately estimate the surface layer fluxes of momentum, heat and moisture. How-

Correspondence to: R. Ramachandran

(radhika@md3.vsnl.net.in) ever, the underlying physics of the exchange processes over the rough seas are not well understood (e.g. DeCosmo et al., 1996; Friehe and Schmidt, 1976; Smith, 1980, 1989). The wind stress and heat flux at the sea surface were, in general, estimated from mean wind and temperature using "bulk" formulas (Blanc, 1985; Bradley et al., 1991; Fairall et al., 1996; Smith, 1988). Empirical coefficients were used to estimate fluxes from gradients using profile measurements between two levels - one at the water surface and the other in the air. This method had a special role because it can be used to estimate fluxes from historical sets of marine weather observations of the "bulk" variable (wind, humidity, air and water temperature) and also because it was the most practical way to input the surface fluxes in numerical models. The accuracy of the estimates depends on how well these exchange coefficients represent the flux processes (Blanc, 1987; Smith et al., 1996). Blanc (1985) gave a detailed comparison of various schemes while Said and Druilhet (1991) provided an exhaustive survey on the aerodynamic coefficients estimated through various methods over different oceanic regions during numerous field experiments; Smith (1989) reported a careful up-to-date review on the status of evaporation measurements. Large et al. (1994) presented a detailed survey on the available schemes to represent a vertical mixing scheme that can be developed into a suitable oceanic boundary layer model for climate studies and detailed a K Profile Parameterization (KPP) model and its successes (Troen and Mahrt, 1986). They reviewed the model and suggested further developments for the KPP model. However, the oceanic database reported by Large et al. (1994) could not explain the queries related to modelling. Despite years of research there is still uncertainty with regard to the behaviour of the various transfer coefficients, in particular for the behaviour of sensible and latent heat flux at wind speeds over $10 \mathrm{~ms}^{-1}$ (see the Joint WCRP/SCOR Working Group Report on Air-Sea Fluxes available at http: //www-pcmdi.llnl.gov/airseawg). The present study is aimed at studying the wind speed dependence of air-sea exchange coefficients of momentum, heat and moisture, crucial for the 
determination of air-sea interface fluxes. The behaviour of roughness lengths for wind $\left(z_{0}\right)$, temperature $\left(z_{0 t}\right)$ and humidity $\left(z_{0 q}\right)$, which plays a key role in the determination of the exchange coefficients, is also addressed in the paper. The study is based on surface layer data collected from a ship-borne platform (Oceanic Research Vessel (ORV) Sagar Kanya) over the western tropical Indian Ocean region during the Intensive Field Phase (IFP-99) of the field experiment "Indian Ocean Experiment (INDOEX)" (Subrahamanyam and Radhika, 2002; Subrahamanyam et al., 2001a, b, 2002, 2003).

\section{INDOEX, IFP-99: Details on the field experiment}

INDOEX, a major international field experiment and research programme, is the result of concerted efforts of several scientific personnel in various inter-disciplinary organizations in India and abroad. The main objective of the INDOEX expedition was to study the radiative forcing by atmospheric aerosols and the migration of the anthropogenic and continental aerosols and pollutants over the Indian Ocean (Ramanathan et al., 1996, 2001 and the references cited therein). The experiment was carried out in four consecutive phases during 1996 to 1999. The Intensive Field Phase of Indian Ocean Experiment (INDOEX, IFP-99) was conducted on board ORV Sagar Kanya during 20 January - 12 March 1999.

\subsection{Experimental set-up}

In the present analysis, air-sea interaction measurements are carried out from a shipboard platform. In contrast to the atmospheric surface layer measurements made over the land, measurements over the oceanic surface are quite difficult, and the possibilities of errors in the measurements are large. In general, a shipboard platform produces two main sources of error in air-sea interaction measurements, viz: - local flow distortion over the bulk of the ship, and contamination of the wind sensors by heat and moisture. Apart from the gross contamination of wind components by motion of the ship, the angular rotation of the instrument axes by pitch and roll cause cross-contamination of horizontal and vertical flux components (Bradley et al., 1991). During INDOEX, IFP-99 campaign, air-sea interaction measurements were carried out by mounting different meteorological sensors on a 7-meter long retractable boom close to the ship bow on board ORV Sagar Kanya (Subrahamanyam and Radhika, 2002; Subrahamanyam et al., 2001b, 2002). Three axis Gill propeller anemometers were used for the wind speed measurements while the relative humidity and ambient air temperature were measured from a humicap sensor. All the sensors mounted on the boom were connected to a data logger (Daq Book) installed at Meteorology Lab on board the ship. Air temperature and relative humidity measurements were acquired at a sampling rate of $0.1 \mathrm{~Hz}$ from a humicap sensor, whereas wind speed measurements were taken at a sampling rate of $10 \mathrm{~Hz}$

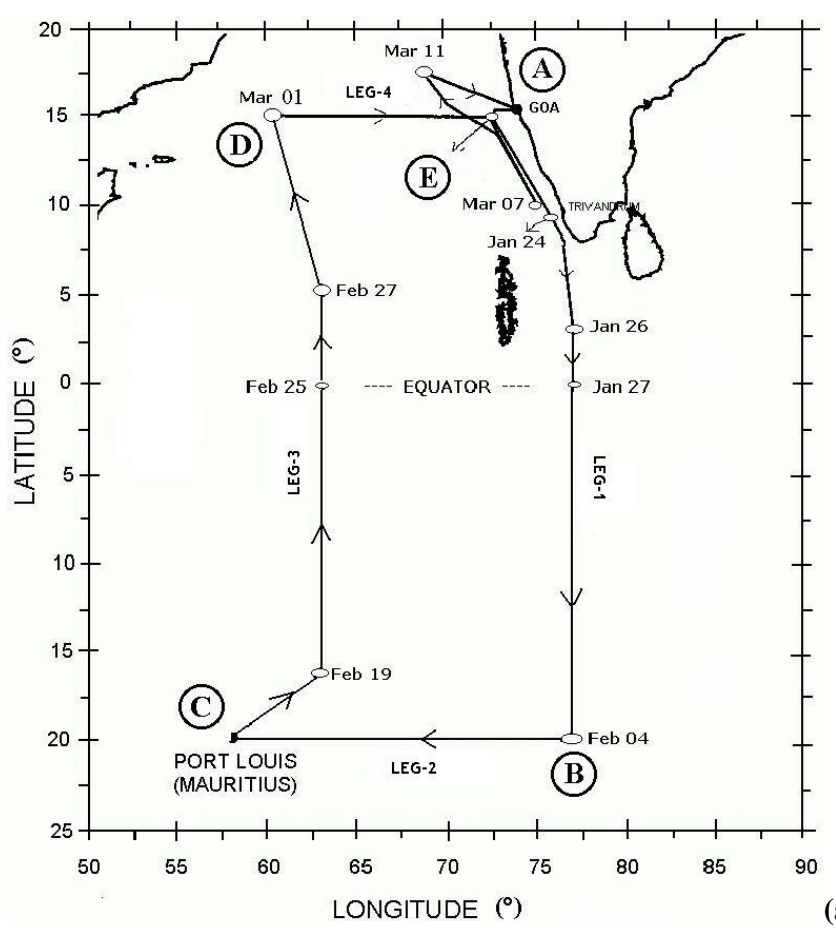

(a)

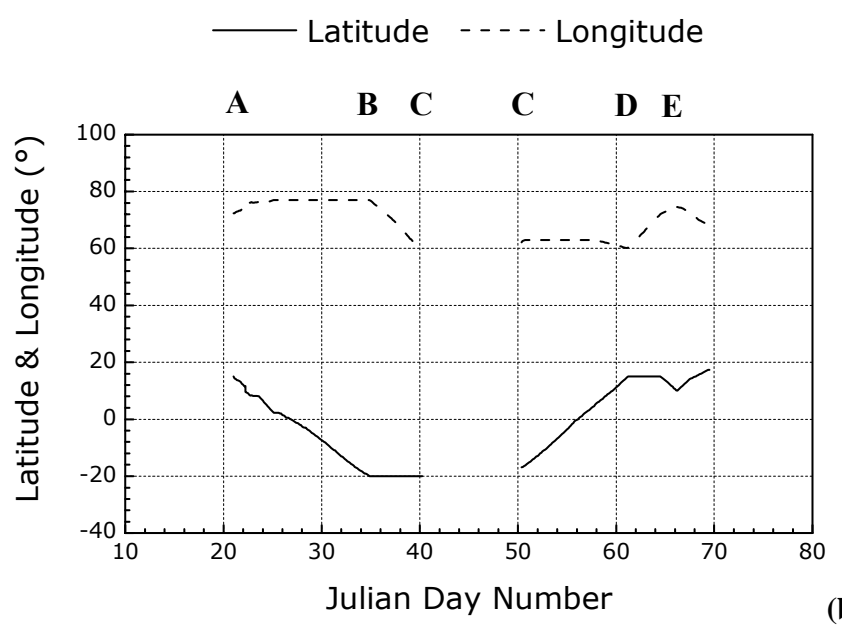

Fig. 1. (a) Cruise track of the field experiment "INDOEX, IFP99" conducted on board ORV Sagar Kanya during 20 January - 12 March1999. (b) Position of ship in terms of geographic latitude and longitude with Julian day number.

from three axis Gill propeller anemometers. Besides these, Dry and Wet Bulb Temperature (DBT and WBT), surface pressure and Sea Surface Temperature (SST) were measured manually at every two-hour interval. A psychrometer was used for measuring the DBT and WBT. SST was measured using the InfraRed (IR) Thermometer. The meteorological sensors mounted on the retractable boom during the campaign provided relatively good sampling for periods when winds were blowing directly toward the bow of the ship; but when the winds are blowing from the stern, the data itself 
may be contaminated by heat and moisture originating from the ship. The wind speed measurements are corrected for the movement of the ship. We could not, however, ascertain the effects on the measurements due to contamination by heat and moisture originating from the ship. In order to couple automatically recorded data from the sensors mounted on the retractable boom with the manually measured parameters at every two-hour interval, hourly averaged values of air temperature, relative humidity and wind speed measurements roughly corresponding to the time of manual measurements are used. The details of a few sensors used in the present study are briefly tabulated in Table 1 . Further details on the accuracies of the measurements made by the sensors and the data acquisition system are reported elsewhere (Subrahamanyam and Radhika, 2002; Subrahamanyam et al., 2001a, 2002).

\subsection{Cruise details}

The field experiment covered a broad oceanic region of the Indian Ocean and the Central Arabian Sea over a latitude range $15^{\circ} \mathrm{N}$ to $20^{\circ} \mathrm{S}$ and a longitude range $63^{\circ} \mathrm{E}$ to $77^{\circ} \mathrm{E}$. Figure 1a shows the cruise track of the campaign. The position of the ship in terms of geographical latitude and longitude with Julian day number is shown in Fig. $1 \mathrm{~b}$ for better reference. The first meridional track approximately along $77^{\circ} \mathrm{E}$ longitude (hereafter, referred to as leg-1) was traversed during the onward track of the cruise between 20 January-4 February 1999, whereas the second meridional track approximately along $63^{\circ} \mathrm{E}$ longitude (hereafter, referred to as leg3 ) took place during the return track of the cruise between 18 February-1 March 1999. Similarly, there are two zonal tracks, the first zonal track along $20^{\circ} \mathrm{S}$ latitude (hereafter, referred to as leg-2) during the onward track of the cruise was conducted during 4-11 February 1999, whereas the second zonal track along $15^{\circ} \mathrm{N}$ latitude (hereafter, referred to as leg-4) was covered between 1-6 March 1999 during the return track of the cruise. The availability of data along two meridional tracks during the cruise made it possible to observe the cross-equatorial gradients in the estimates of air-sea exchange parameters, while the spatial variability along the two zonal tracks, one located in the Northern Hemisphere, and the other in the Southern Hemisphere gave an opportunity for assessing the behaviour of the estimated parameters in the two hemispheres (Subrahamanyam and Radhika, 2002; Subrahamanyam et al., 2001b, 2002). In the present paper, we describe the spatio-temporal variation of air-sea interaction parameters for all four legs separately in relation to the prevailing meteorological conditions.

\section{Method of analysis}

The bulk aerodynamic method estimates the turbulent exchanges of downward momentum flux or stress $(\tau)$ in $\mathrm{Nm}^{-2}$, sensible heat flux $\left(H_{S}\right)$ and latent heat flux $\left(H_{L}\right)$ in $\mathrm{Wm}^{-2}$. Computation of the surface layer fluxes using this method re- quires determination of the exchange coefficients $\left(C_{D}, C_{H}\right.$ and $C_{E}$ ). In the present analysis, we have estimated the values of the empirical exchange coefficients $C_{D}, C_{H}$ and $C_{E}$ through an iterative scheme based on a revised bulk algorithm discussed in detail in Subrahamanyam and Radhika (2002). The basic methodology is summarized as follows: turbulent exchange processes in the atmospheric surface layer are commonly formulated within the framework of Monin-Obukhov similarity theory (Bradley et al., 1991; Stull, 1988). Based on the integrated forms of the profile relations that considered the non-diabatic cases as well (Businger et al., 1971), the friction velocity $(u *)$ and scaling parameter for temperature and humidity $(\theta *$ and $q *)$ are given as:

$\left.u *=\left[k \cdot\left(U_{10}-U_{s}\right)\right] /\left[\ln \left(z / z_{0}\right)-\Psi_{m}\right)\right]$

$\theta *=\left[k \cdot\left(\theta_{10}-T_{s}\right)\right] /\left[\ln \left(z / z_{0 t}\right)-\Psi_{t}\right]$

$q *=\left[k \cdot\left(q_{10}-q_{s}\right)\right] /\left[\ln \left(z / z_{0 q}\right)-\Psi_{q}\right]$,

where $U, \theta$ and $q$ represent the mean wind speed $\left(\mathrm{ms}^{-1}\right)$, potential temperature $(K)$ and specific humidity $\left(\mathrm{kg}^{\mathrm{kg}} \mathrm{kg}^{-1}\right)$, respectively. The subscripts "S" and " 10 " represent the sea surface and measurement height, $z(=10 \mathrm{~m})$, respectively, $T_{S}$ is the sea surface temperature $(K)$ and $k(=0.4)$ is the von Karman constant. In Eqs. (1), (2) and (3) the $z_{0}, z_{0 t}$ and $z_{0 q}$ are the roughness lengths for wind, temperature and humidity, respectively, whereas terms " $\Psi_{m}$ ", " $\Psi_{t}$ " and " $\Psi_{q}$ " are the integrated forms of the functions of the lower level stability $(z / L)$, for wind speed, temperature and humidity, respectively. The integrated stability functions " $\Psi_{m}$ ", " $\Psi_{t}$ " and " $\Psi_{q}$ " for stable and unstable stratification are defined as (DeCosmo et al., 1996; Dyer, 1974; Smith, 1988):

$\Psi_{m}=\Psi_{t}=\Psi_{q}=-5 .(z / L)$

for stable stratification. For unstable stratification, the integrated stability functions are defined as (DeCosmo et al., 1996; Paulson, 1970; Smith, 1988):

$\Psi_{m}=2 \cdot \ln [(1+x) / 2]+\ln \left[\left(1+x^{2}\right) / 2\right]-2 \cdot \tan ^{-1}(x)+(\pi / 2)(5)$

$\Psi_{t}=\Psi_{q}=2 \cdot \ln \left[\left(1+x^{2}\right) / 2\right]$,

where " $x$ " is given by:

$x=[1-16 .(z / L)]^{1 / 4}$.

In the above equations, $L$ is the Monin-Obukhov stability length, and it has been derived using (Lo, 1993):

$L=\left(T_{V} \cdot u *^{2}\right) /\left(k \cdot g \cdot \theta_{V *}\right)$,

where "g" $\left(=9.8 \mathrm{~ms}^{-2}\right)$ is the acceleration due to gravity, $T_{V}$ (virtual temperature at the measurement height, in Kelvin) is used in order to include the effects of water vapor content on the density stratification, and $\theta_{V *}$ is the scaling parameter for virtual temperature. To initialize the calculations, an estimated value of the velocity roughness length, $z_{0} \approx 10^{-4} \mathrm{~m}$ is 
Table 1. Accuracy of measurement of a few sensors

\begin{tabular}{|c|c|c|c|c|}
\hline Sr.No. & Sensor/Instrument & $\begin{array}{l}\text { Measured } \\
\text { Parameter }\end{array}$ & Manufacturer & Accuracy \\
\hline 1. & $\begin{array}{l}\text { Gill Propeller } \\
\text { Anemometer }\end{array}$ & $\mathrm{U}, \mathrm{V}$ and $\mathrm{W}$ & $\begin{array}{l}\text { RM Young, Michigan, } \\
\text { 49686, USA }\end{array}$ & $0.1 \mathrm{~ms}^{-1}$ \\
\hline 2. & Humicap & $\begin{array}{l}\text { Air Temperature } \\
\text { Relative Humidity }\end{array}$ & $\begin{array}{l}\text { RM Young, Michigan, } \\
49686, \text { USA }\end{array}$ & $\begin{array}{l}0.3^{\circ} \mathrm{C} \text { for air temperature } \\
3 \% \text { for relative humidity }\end{array}$ \\
\hline 3. & $\begin{array}{l}\text { IR } \\
\text { Thermometer }\end{array}$ & $\begin{array}{l}\text { Sea (Skin) Surface } \\
\text { Temperature }\end{array}$ & $\begin{array}{l}\text { Telatemp, Fullerton, } \\
\text { CA 92635,USA }\end{array}$ & $0.5^{\circ} \mathrm{C}$ \\
\hline
\end{tabular}
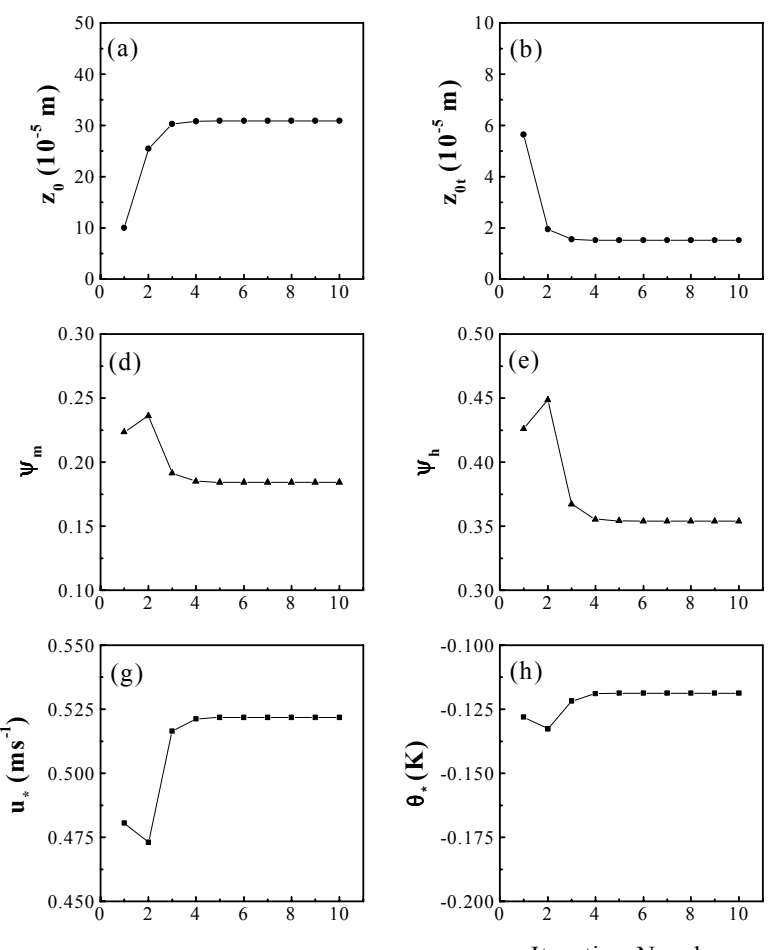

Iteration Number
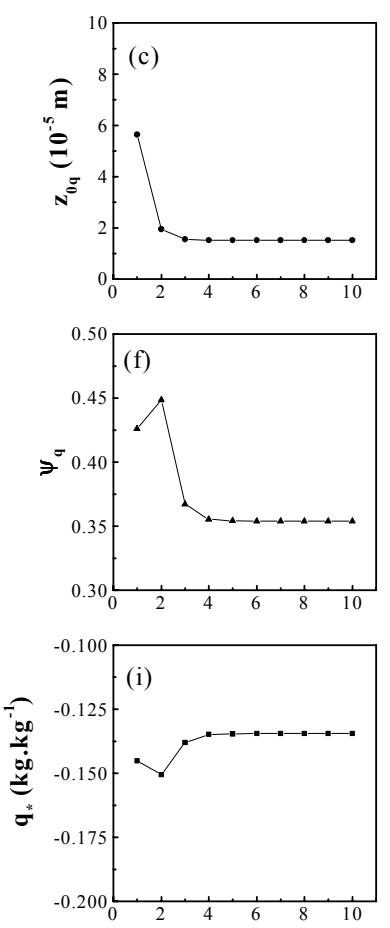

Fig. 2. Iterative estimates of (a) velocity roughness length $\left(z_{0}, \times 10^{-5} \mathrm{~m}\right)$, (b) roughness length for temperature $\left(z_{0 t}, \times 10^{-5} \mathrm{~m}\right),(\mathbf{c})$ roughness length for humidity $\left(z_{0 q}, \times 10^{-5} \mathrm{~m}\right)$, (d) stability function $\Psi_{m}$ (e) stability function $\Psi_{h}$, (f) stability function $\Psi_{q}$, (g) scaling parameter for wind $u *\left(\mathrm{~ms}^{-1}\right)$, (h) scaling parameter for temperature $\theta *$ $(K)$ and (i) scaling parameter for humidity $q *\left(\mathrm{~kg} \cdot \mathrm{kg}^{-1}\right)$ with the number of iterations. assumed applicable for the sea surface under moderate wind conditions (Lo, 1993). For the first iteration, the stability functions " $\Psi_{m}$ ", " $\Psi_{t}$ " and " $\Psi_{q}$ " are assumed to be zero, the wind speed at sea surface $\left(U_{S}\right)$ is taken as zero (Lo, 1993) and the relative humidity at the sea surface is assumed to be 98\% (Kraus and Businger, 1994). The neutral stability transfer coefficients are uniquely related to the roughness lengths $z_{0 x}$ ( $z_{0}$ in case of wind profiles, $z_{0 t}$ in case of temperature profiles and $z_{0 q}$ in case of humidity profiles) as:

$C_{x N}=\left[k^{2} / \ln \left(z / z_{0}\right) \cdot \ln \left(z / z_{0 x}\right)\right]$.

Smith (1988) showed that the neutral stability transfer coefficients for heat and moisture $\left(C_{H N}\right.$ and $\left.C_{E N}\right)$ are approximately independent of wind speed with values of $1.15 \times 10^{-3}$ at a reference height of $10-\mathrm{m}$. Therefore, solving the above equation for the roughness length, with the prescribed value of $\left(C_{H N}\right.$ and $C_{E N}\left(=1.15 \times 10^{-3}\right)$, we obtain the roughness length for temperature and humidity $\left(z_{0 t}\right.$ and $\left.z_{0 q}\right)$ as:

$z_{0 t}=z_{0 q}=z / \exp \left[k^{2} /\left(1.15 \times 10^{-3}\right) \cdot \ln \left(z / z_{0}\right)\right]$.

With the estimates of friction velocity obtained from Eq. (1), we follow the empirical relation for roughness length suggested by Charnock (1955). The roughness length $\left(z_{0}\right)$ is represented as the sum of two terms, one due to Charnock (1955) $\left.\left(z_{0 c}=\alpha . u *^{2} / g\right)\right)$ and the other is the viscous term $\left(z_{0 s}=\beta . v / \alpha . u *\right)$ due to Smith (1988), (Fairall et al., 1996; Grachev and Fairall, 1997):

$z_{0}=\left(\alpha . u *^{2} / g\right)+(\beta . v / \alpha . u *)$,

where $\alpha$ is the Charnock "constant", for which values between 0.010 and 0.035 are cited in literature (Garratt, 1992, Table 4.1, pp. 99). In the present analysis, the value of $\alpha$ is taken as 0.011 (after Smith, 1988). The term " $v$ " $\left(=14 \times 10^{-6} \mathrm{~m}^{2} \mathrm{~s}^{-1}\right)$ represents the dynamic viscosity of 
air. For wind speeds above about $6 \mathrm{~ms}^{-1}$, the second term in Eq. (11) is negligible. A value of $\beta=0.11$ has been used from wind tunnel experiments following Smith et al. (1996). The roughness length $\left(z_{0}\right)$ estimate obtained from Eq. (11) is then substituted into Eq. (10) to obtain new estimates of roughness length for heat and moisture $\left(z_{0 t}\right.$ and $\left.z_{0 q}\right)$. The wind speed at the sea surface $\left(U_{S}\right)$, commonly known as drift velocity, is taken as zero for the first iteration. Smith (1988) performed the above calculations for a range of wind speeds and sea-air (virtual) temperature differences by iterating $u *$ and $\theta *$ until the neutral flux coefficients matched their specified values. Here, the value of the drift velocity (wind speed at sea surface, $U_{s}$ in Eq. 1) is taken as zero. However, it has been verified experimentally and theoretically, that the surface drift velocity is approximately equal to $u *$ (e.g. Hicks, 1972; Lo, 1993; Roll, 1965). Therefore, in the revised bulk algorithm (Subrahamanyam and Radhika, 2002), the iteration is carried out for obtaining the estimates of $u *, \theta *$ and $q *$ in such a way that for all subsequent iterations the estimated value of $u *$ from the preceding iteration is substituted in place of drift velocity $\left(U_{s}\right)$. The integrated stability functions $\left(\Psi_{m}, \Psi_{t}\right.$ and $\left.\Psi_{q}\right)$ are estimated using equations suggested in Smith (1988). Now, the estimated values of roughness lengths $\left(z_{0}, z_{0 t}\right.$ and $\left.z_{0 q}\right)$ and the stability functions ( $\Psi_{m}$, $\Psi_{t}$ and $\Psi_{q}$ ) are substituted into Eqs. (1), (2) and (3) to determine new estimates of $u *, \theta *$ and $q *$. Using these, the stability functions $\left(\Psi_{m}, \Psi_{t}\right.$ and $\left.\Psi_{q}\right)$ and the roughness lengths $\left(z_{0}, z_{0 t}\right.$ and $\left.z_{0 q}\right)$ are determined again and the iteration is repeated, untill the $u *, \theta *, q *$ and $z_{0}$ calculated from the two consecutive iterations converge. Figure 2 shows the gradual convergence of the estimates of the roughness lengths $\left(z_{0}\right.$, $z_{0 t}$ and $z_{0 q}$ ) shown in Figs. 2a, b and c, respectively), the stability functions $\left(\Psi_{m}, \Psi_{t}\right.$ and $\left.\Psi_{q}\right)$ shown in Figs. 2 d, e and $\mathrm{f}$, respectively), and the scaling parameters $(u *, \theta *$ and $q *$ shown in Figs. 2g, h and i, respectively), through the iterations. The iterative method has two main advantages: (1) the surface drift velocity is taken as zero only for the first iteration, afterwards it is replaced by $u *$, thereby giving better and more accurate values of other parameters in the ensuing iterations; (2) for initialing the calculations, the sea surface roughness length $\left(z_{0}\right)$ is taken as $10^{-4}-\mathrm{m}$ (Lo, 1993). However, an estimate of $z_{0}$ based on the iteration of the surface layer data collected during the INDOEX campaign covering a broad oceanic region will be a better representation of actual $z_{0}$ against the initially assumed value of $10^{-4} \mathrm{~m}$. Figure 2 represents the converging values of the estimates after successive iterations. These final estimates of $u *, \theta *$ and $q *$ are then used for the computation of the drag coefficient $\left(C_{D}\right)$ and sensible heat and water vapour exchange coefficients $\left(C_{H}\right.$ and $\left.C_{E}\right)$ as follows (Byun, 1990; DeCosmo et al., 1996):

$$
\begin{aligned}
& C_{D}=u *^{2} /\left(U_{10}-U_{s}\right)^{2} \\
& C_{H}=u * . \theta * /\left(U_{10}-U_{s}\right) .\left(\theta_{10}-T_{S}\right) \\
& C_{E}=u * . q * /\left(U_{10}-U_{S}\right) .\left(q_{10}-q_{s}\right) .
\end{aligned}
$$

Cruise leg-1 (January 20 - February 04, 1999)

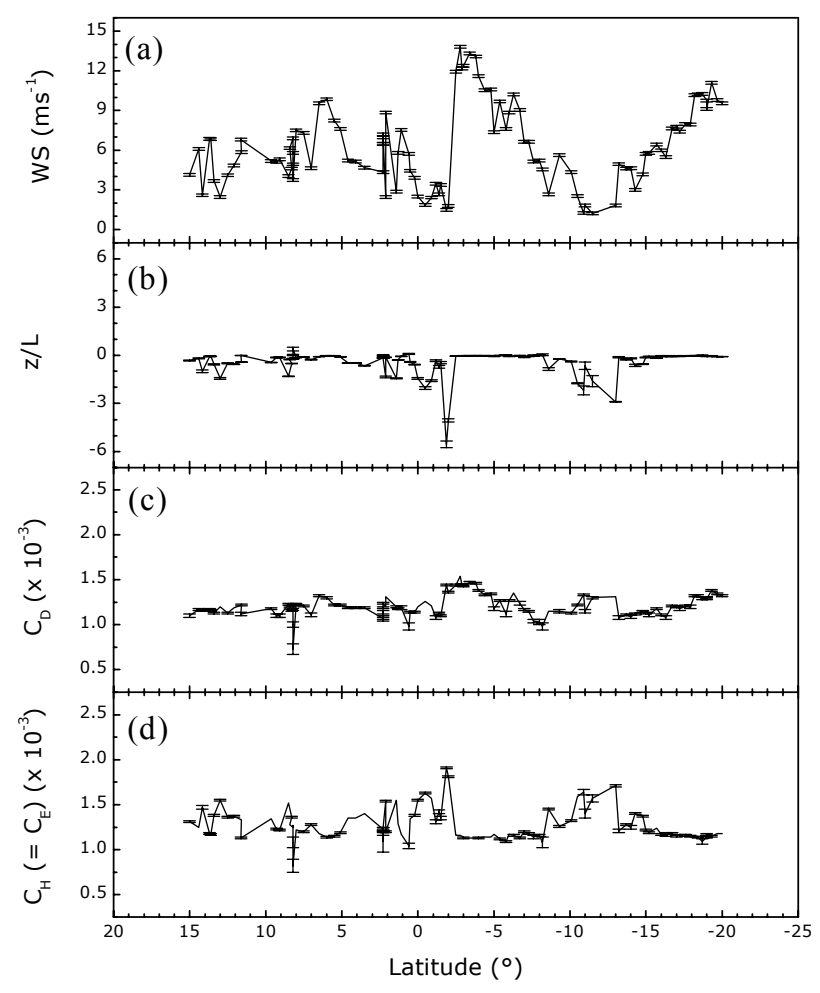

Fig. 3. Latitudinal variation of air-sea interaction parameters along cruise leg-1. (a) Wind Speed $\left(W S, \mathrm{~ms}^{-1}\right)$; (b) Stability Parameter $(z / L)$; (c) Drag Coefficient $\left(C_{D}, \times 10^{-3}\right)$; (d) Sensible Heat and Water Vapour exchange coefficients $\left(C_{H}\right.$ and $\left.C_{E}, \times 10^{-3}\right)$.

\section{Results and discussion}

The meteorological conditions prevailing over the region of tropical Indian Ocean and Central Arabian Sea along the cruise tracks during the entire campaign can be summarized as follows: during the forward track of the cruise, most of the days were cloudy. Along leg-1, heavy rains were observed in the latitude range $2^{\circ} \mathrm{S}$ to $4^{\circ} \mathrm{S}$. During leg-3 and leg-4, i.e. the return track of the cruise, barring a few days, most of the days were clear, bright and sunny. During the INDOEX, IFP99 (20 January- 12 March 1999), the Inter-Tropical Convergence Zone (ITCZ) was located in the Southern Hemisphere, around $5^{\circ} \mathrm{S}$ and was migratory (Madan et al., 1999). Subrahamanyam and Radhika (2002) have described the prevailing meteorological conditions in terms of surface observations along the cruise track in detail. Since the aim of this paper is to study the wind speed dependence of air-sea exchange parameters, we present the spatio-temporal variation of these parameters along the cruise track with the variation of wind speed. In the following sub-sections, we shall describe the spatio-temporal variation of boundary layer parameters along the cruise track (Figs. 3-6, respectively). In each of these figures, four panels $(\mathrm{a}-\mathrm{d})$ represent the spatio-temporal variation of the following parameters: (a) Wind Speed (WS, $\mathrm{ms}^{-1}$ ); (b) Stability Parameter $(z / L)$; (c) Drag Coefficient 


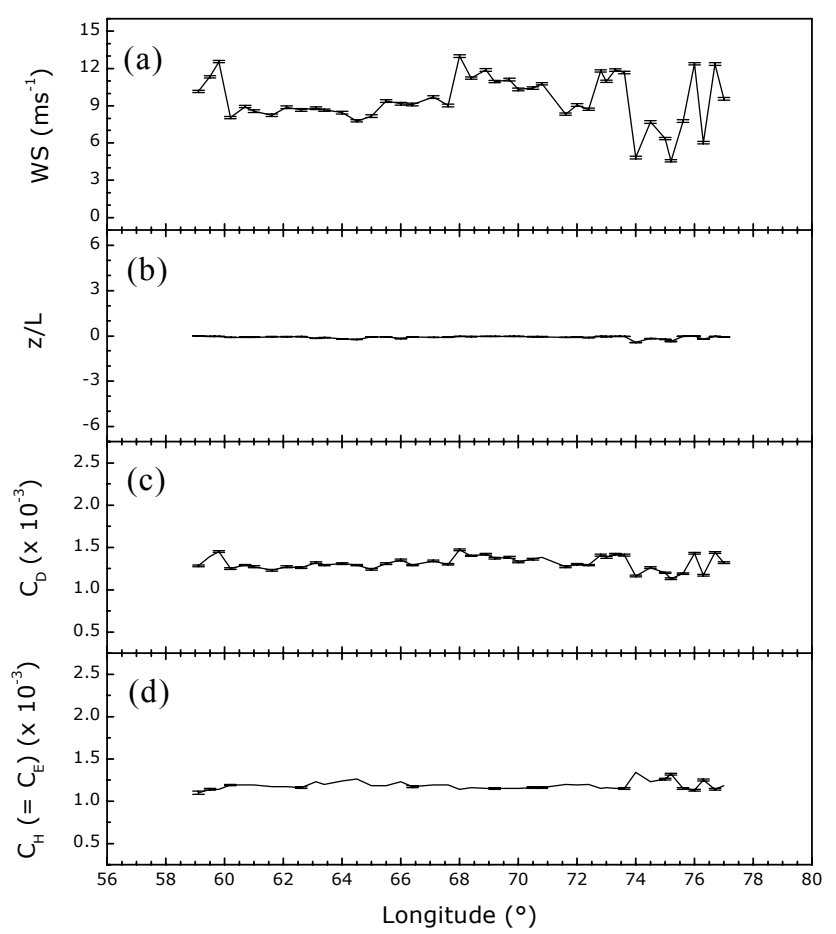

Fig. 4. Longitudinal variation of air-sea interaction parameters along cruise leg-2. (a) Wind Speed $\left(W S, \mathrm{~ms}^{-1}\right)$; (b) Stability Parameter $(z / L)$; (c) Drag Coefficient $\left.\left(C_{D}, \times 10^{-3}\right)\right)$; (d) Sensible Heat and Water Vapour exchange coefficients $\left(C_{H}\right.$ and $C_{E}, \times$ $\left.10^{-3}\right)$.

$\left(C_{D}\right)$; (d) Sensible Heat and Water Vapour exchange coefficients $\left(C_{H}\right.$ and $\left.C_{E}\right)$, respectively. The error bars represent the uncertainty in the measurements and the estimated parameters due to uncertainty in the instrumentation errors.

\subsection{Spatio-temporal variations in air-sea exchange param- eters along the cruise track}

\subsubsection{Cruise leg-1 (meridional track-AB)}

Figure 3 shows the latitudinal variation of air-sea interaction parameters along cruise leg-1, marked "AB" in Fig. 1a. This part of the cruise was traversed in a period of almost 15 days from 21 January-4 February 1999. During this leg, the ITCZ was located between the equator and $10^{\circ} \mathrm{S}$. Intense convection and associated rainfall are also reported in this latitudinal belt (Subrahamanyam et al., 2002, 2003). Along the cruise leg-1, WS varied within a range 1 to $14 \mathrm{~ms}^{-1}$, with a peak value of about $14 \mathrm{~ms}^{-1}$ between the equator and the $3^{\circ} \mathrm{S}$ latitudinal belt (Fig. 3a). As the ship crossed $10^{\circ} \mathrm{S}$ latitude, it experienced a gradual increase in $W S$ magnitudes and became maximum at the tip of the leg at $20^{\circ} \mathrm{S}$, i.e. at point "B" (Fig. 1a). The weekly averaged wind field analysis provided by the National Centre for Medium Range Weather Forecasting (NCMRWF, New Delhi, India) reported by Madan

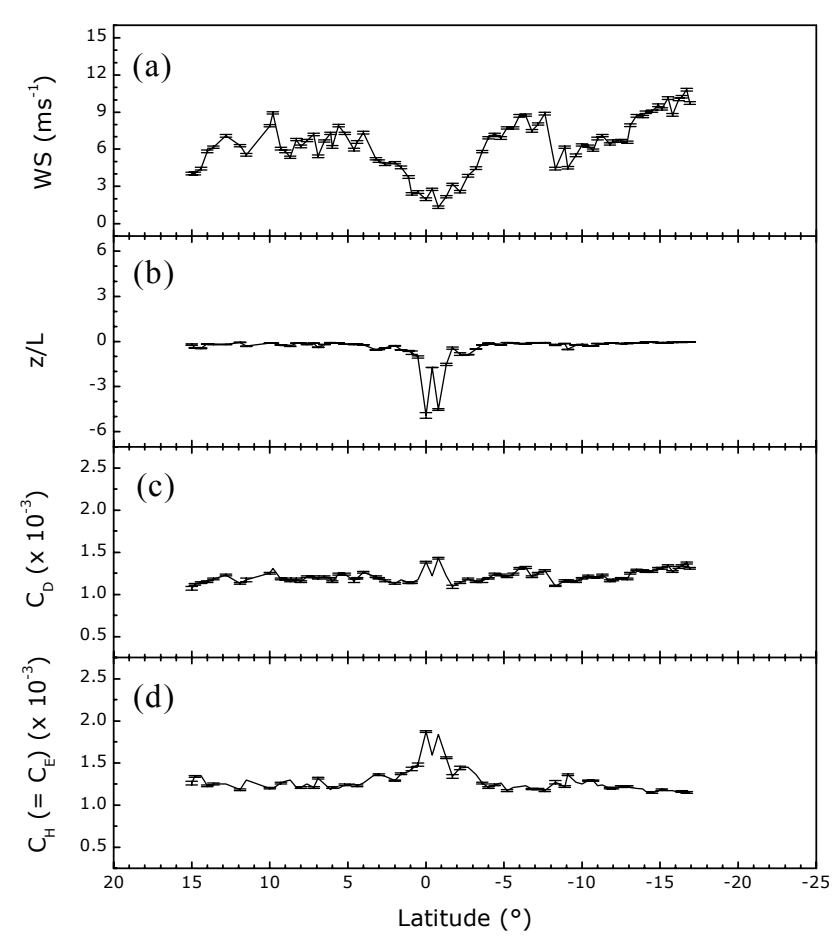

Fig. 5. Same as Fig. 3, but for cruise leg-3.

et al. (1999) also supports the surface observations shown in these figures (Subrahamanyam and Radhika, 2002). Figure $3 \mathrm{~b}$ shows the latitudinal variation in stability parameter values $(z / L)$. The Monin-Obukhov stability parameter $(z / L)$ is a measure of atmospheric stability. Negative values of $z / L$ correspond to unstable conditions while positive values represent stable conditions (Stull, 1988). Except for a few regions, the entire cruise leg-1 experienced near-neutral conditions, with $z / L \approx 0$. Panels "c" and "d" of Fig. 3 shows the variation in air-sea exchange coefficients, $C_{D}$ and $\left(C_{H}=C_{E}\right)$, respectively. A small change in the magnitudes of these coefficients can lead to a large variation in the flux magnitudes. Along cruise leg-1, on average, $C_{D}$ values were about 1.20 while $C_{H}$ values were about 1.26 (Figs. $3 \mathrm{c}$ and d). It has to be noted that along ITCZ regions near the equatorial belt, the air-sea exchange coefficients also show considerable gradients, which, in turn, affect the magnitudes of air-sea interface fluxes over these regions.

\subsubsection{Cruise leg-2 (zonal track-BC)}

Longitudinal variation of observed and estimated parameters along cruise leg-2 is shown in Fig. 4. Cruise leg-2 (marked "BC" in Fig. 1a) took place between 4-11 February 1999. The fact that this part of the cruise took place within a period of a week and also that it had a zonal movement, one does not observe a drastic spatial variation in the observed parameters or in the estimates. As can be seen from the figure, mag- 
Cruise leg-4 (March 01 - 06, 1999)

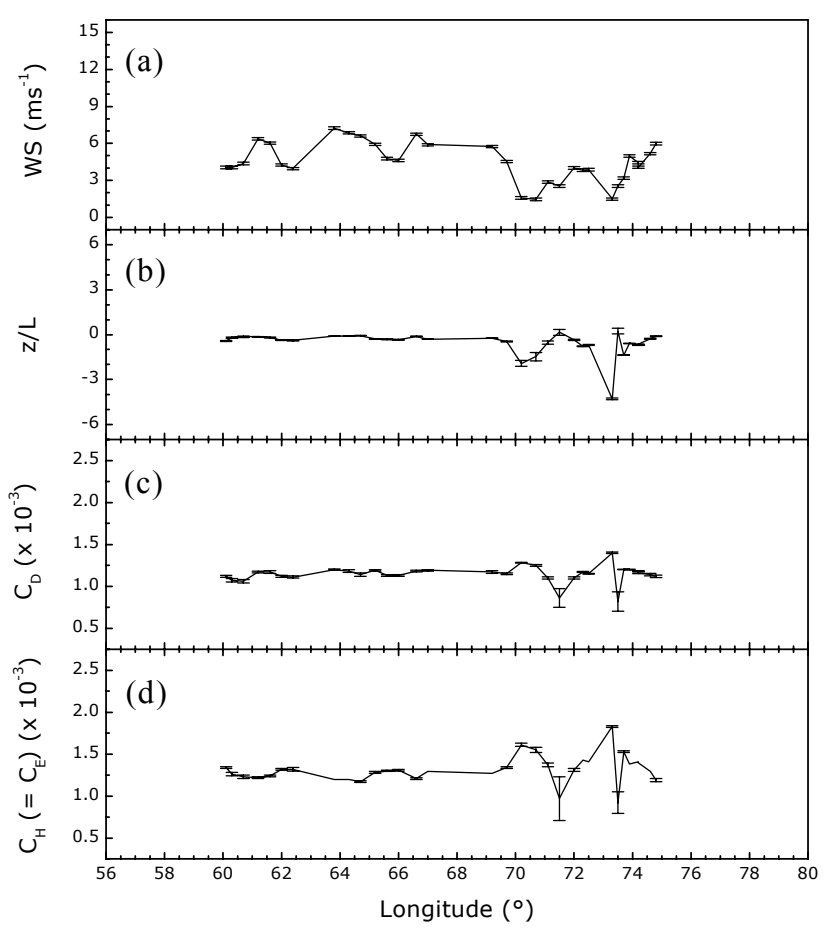

Fig. 6. Same as Fig. 4, but for cruise leg-4.

nitudes of wind speed were larger along leg-2, and broadly it varied within a range of 4.6 to $13 \mathrm{~ms}^{-1}$, with an average value of about $9.5 \mathrm{~ms}^{-1}$ (Fig. 4a). It has to be noted that the wind field analysis provided by NCMRWF, New Delhi (Madan et al., 1999) for the same period also shows strong easterly winds prevailing over this zonal belt. The stability parameter $(z / L)$ and the air-sea exchange coefficients $\left(C_{D}\right.$ and $C_{H}$ ) do not show any large variations along leg-2; $z / L$ values remained near zero, showing near-neutral stability of the atmosphere (Fig. 4b). Average drag coefficient values were about 1.31 (Fig. 4d) while $C_{H}$ values were about 1.18 (Fig. 4d).

\subsubsection{Cruise leg-3 (meridional track-CD)}

Figure 5 shows the latitudinal variation of air-sea interaction parameters for leg-3 covered during the return track of the cruise. This leg (marked "CD" in Fig. 1a) was traversed during 18 February-1 March 1999. It is to be noted that the prevailing conditions were different from that during the first meridional track- $\mathrm{AB}$, which took place about 2-3 weeks earlier. Also, the second meridional track was along $63^{\circ} \mathrm{E}$ against $77^{\circ} \mathrm{E}$ longitude for the first meridional track. Most of the days during leg- 3 were cloud free, bright and sunny. However, the ITCZ had weakened and its position was between the equator and the $10^{\circ} \mathrm{S}$ latitudinal belt. Moderate to high wind speeds were observed along leg-3 of the cruise track. The southern part of leg-3 experienced large winds while the equatorial belt experienced low winds

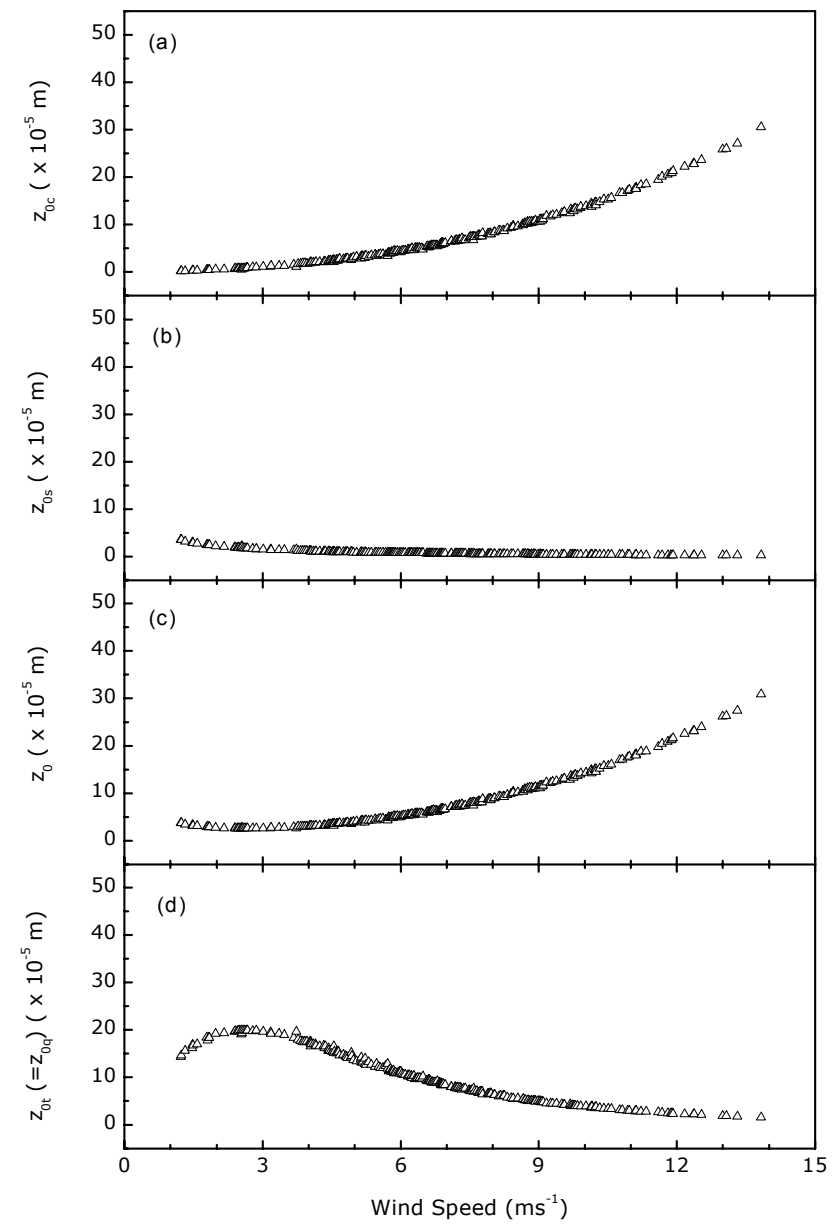

Fig. 7. Wind speed dependence of roughness length: (a) Velocity roughness length $-z_{0 c}\left(\times 10^{-5} \mathrm{~m}\right)$ (after Charnock, 1955); (b) Velocity roughness length $-z_{0 s}\left(\times 10^{-5} \mathrm{~m}\right)$ (after Smith, 1988); (c) Velocity roughness length $z_{0}$ (sum of $z_{0 c}$ and $\left.z_{0 s}\right),\left(\times 10^{-5} \mathrm{~m}\right.$ ); (d) Roughness length for temperature (and humidity) $z_{0 t}\left(=z_{0 q}\right)$, $\left(\times 10^{-5} \mathrm{~m}\right)$.

(Fig. 5a). Except for regions near the equator, the stability parameter and air-sea exchange coefficients remained constant (Figs. 5b, c and d). Drag coefficient values were about 1.21, while $C_{H}$ remained more or less constant with a value of about 1.27 (Figs. 5c and d).

\subsubsection{Cruise leg-4 (zonal track-DE)}

Figure 6 shows the longitudinal variation of the air-sea interaction parameters for leg-4, covered between 1-6 March 1999. As for the longitudinal variations observed along leg2 , this leg also does not show large spatial gradients in air-sea exchange parameters. Along leg-4 wind speed magnitudes were low in the range 1.5 to $7.2 \mathrm{~ms}^{-1}$ (Fig. 6a). The eastern sector of leg-4 shows unstable atmospheric conditions with negative values of $z / L$ (Fig. 6b). Figures $6 \mathrm{c}$ and d show the longitudinal variation of $C_{D}$ and $C_{H}$, respectively. From the figure, it can be seen that there is no large variation in the parameters as was seen in the meridional tracks. 


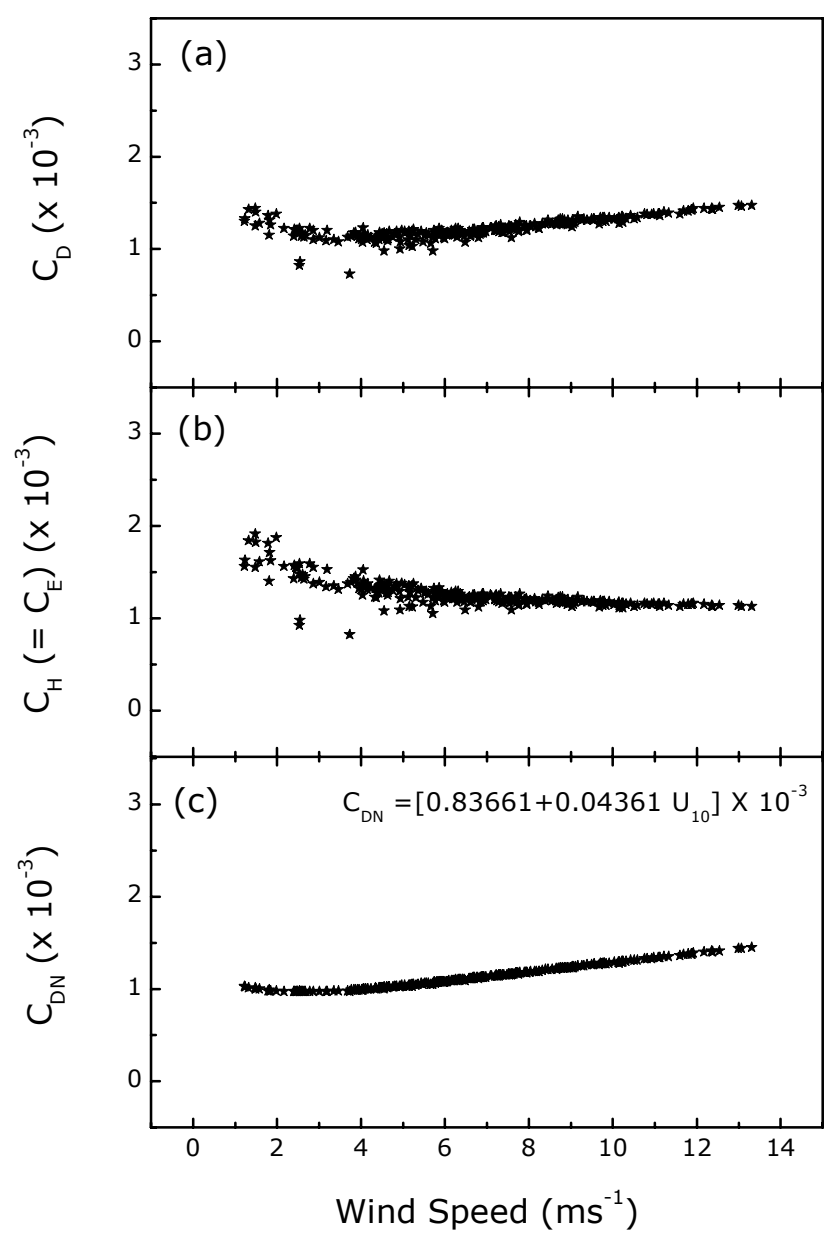

Fig. 8. Wind speed dependence of air-sea exchange coefficients: (a) $C_{H}\left(=C_{E}\right) ;(\mathbf{b}) C_{D}$ and (c) $C_{D N}$.

\subsection{Variation of surface roughness length $\left(z_{0}, z_{0 t}\right.$ and $\left.z_{0 q}\right)$}

Now with the available estimates of air-sea exchange parameters, we attempt to study the wind speed dependence of surface roughness length and air-sea exchange coefficients, imperative in the estimation of air-sea interface fluxes. The roughness length $\left(z_{0 x}\right)$ can be physically interpreted as the virtual origins of the profiles of the concerned parameter " $x$ " (in this case, " $x$ " can be winds, temperature or humidity). It can be determined by plotting $\ln (z)$ vs. the measured winds at that height, and extrapolating the best-fit straight line down to the level where the winds are zero, with its intercept on the ordinate axis being $\ln \left(z_{0}\right)$. One should note that this is only a mathematical or graphical procedure for estimating the roughness length $\left(z_{0}\right)$. In practice, measurements of any meteorological parameter over the oceanic surface at various heights are quite difficult. Therefore, in the present study, the roughness length is estimated using an iterative scheme described in Sect. 3.

We now attempt to study the variation of surface roughness length in relation to the surface wind speeds. Figure 7 shows the wind speed dependence of velocity roughness length $z_{0}$. As per the definition of velocity roughness length (see Eq. (11), Sect. 3), $z_{0 c}$ is given as the sum of two terms, $z_{0 c}$ and $z_{0 s}$. The variation of the two independent terms, $z_{0 c}$ and $z_{0 s}$ are shown separately in the top two panels (Figs. 7a and b), followed by the variation of $z_{0}$ and $z_{0 t}\left(=z_{0 q}\right)$ in the two bottom panels (Figs. 7c and d). From Fig. 7a, it is clear that there is a significant increase in the roughness $z_{0 c}$ (defined by Charnock, 1955) with increasing wind speed. In contrast to the variation of the first term $z_{0 c}$, we see a decreasing trend for the variation of second term $z_{0 s}$ (the viscous term defined by Smith, 1988) with increasing wind speed (Fig. 7b). It can be seen from Fig. 7b that for winds above $6 \mathrm{~ms}^{-1}$, as expected, the viscous term $\left(z_{0 s}\right)$ has negligible influence, and the value drops to zero in large winds and it dominates in the lower wind speed regime. The variation of velocity roughness length, which is defined as the sum of $z_{0 c}$ and $z_{0 s}$, with wind speed, is shown in Fig. 7c with the variation of wind speed. The wind speed dependence of $z_{0}$ reflects the behaviour of both the terms collectively. From Fig. 7c, we can see that the magnitude of velocity roughness length $\left(z_{0}\right)$ decreases from $9 \times 10^{-5} \mathrm{~m}$ to 3 $\times 10^{-5} \mathrm{~m}$, when the magnitude of the winds changed from $1 \mathrm{~ms}^{-1}$ to $3 \mathrm{~ms}^{-1}$. Once it exceeds a value of $3 \mathrm{~ms}^{-1}$, there is a sharp increase in the magnitude of $z_{0}$, and it reaches up to $30 \times 10^{-5} \mathrm{~m}$ at about $14 \mathrm{~ms}^{-1}$. Figure $7 \mathrm{~d}$ shows the variation of roughness lengths for temperature and humidity $\left(z_{0 t}\right.$ and $z_{0 q}$ ) with increasing wind speed. When the winds are greater than $3 \mathrm{~ms}^{-1}$, there is clear evidence that the surface roughness for temperature and humidity decreases with increasing wind speed. However, in the wind speed regime of 0 to $3 \mathrm{~ms}^{-1}$, there is a sharp increase in the magnitude of $z_{0 t}$ $\left(=z_{0 q}\right)$ with increasing wind speeds. This behaviour of $z_{0 t}$ and $z_{0 q}$ at lower wind speeds can again be explained due to the viscous term, shown in Eq. (11), which determines the magnitude of $z_{0}$. When we compare the variation of $z_{0}$ and $z_{0 t}\left(=z_{0 q}\right)$ with wind speed, we notice that for low winds (when winds are less than $7 \mathrm{~ms}^{-1}$ ), the magnitudes of $z_{0 t}$ (= $\left.z_{0 q}\right)$ are large compared to $z_{0}$; however, at larger wind speeds $\left(>7 \mathrm{~ms}^{-1}\right)$, the $z_{0}$ values are considerably larger than that of the $z_{0 t}\left(=z_{0 q}\right)$ values.

Malhi (1996) gives a detailed analysis of the behaviour of the roughness length for temperature $\left(z_{0 t}\right)$ over heterogeneous surfaces over land. His analysis demonstrated that certain transfer processes within the interfacial sub-layer, notably molecular diffusion and free convection, might induce a dependency of $z_{0 t}$ on wind speed. Furthermore, in this study the roughness length for temperature $\left(z_{0 t}\right)$ shows a decreasing trend with increasing wind speed. Except for the lower wind speed regime ( 0 to $3 \mathrm{~ms}^{-1}$ ), our analysis also shows a decreasing trend for $z_{0 t}$ and $z_{0 q}$ with increasing wind speed. Turbulence alone cannot transfer heat and moisture over the air-sea interface; therefore, we have to consider molecular effects, in addition to turbulent transfer, for studying the behaviour of $z_{0 t}$ and $z_{0 q}$. Molecular conduction of heat and molecular diffusion of tracers cause transport between the surface and the lowest few millimeters of air. With increasing wind speed, the formation of sea waves lead to dominance of turbulence over molecular diffusion at the lowest few cen- 
timeters of air, which would lead to a further decrease in the magnitude of $z_{0 t}$ and $z_{0 q}$.

\subsection{Variation of air-sea exchange coefficients}

Figure 8 shows the wind speed dependence of bulk transfer coefficients for momentum, heat and moisture computed using Eqs. (12) to (14). In the figure, the top panel (8a) shows the wind speed dependence of drag coefficients and Fig. $8 \mathrm{~b}$ that of the sensible heat and water vapor exchange coefficients. From Fig. 8a, we notice that the drag coefficient increases with increasing wind speed. Over a wind speed regime of $1-14 \mathrm{~ms}^{-1}$ (observed during INDOEX, IFP99 campaign), the variation of drag coefficient lies within a range $0.7-1.5\left(\times 10^{-3}\right)$; however, in the lower wind speed regime (i.e. $1-4 \mathrm{~ms}^{-1}$ ), there is a slight decrease in the magnitude of drag coefficient. Smith (1988) also reported a similar variation of drag coefficient at a lower wind speed regime. He observed that the value of the exchange coefficient depends strongly on the stability stratification at low wind speeds, but such an influence was not seen with increasing wind speed. Recently, Wu (1994) suggested that the closely packed capillary waves associated with surface tension partly explain the large drag coefficients at weak winds. Geernaert et al. (1988), Bradley et al. (1991) and Greenhut and Khalsa (1995) have also reported a similar increase in drag coefficient values at low wind speeds. In contrast to the variation of drag coefficient $\left(C_{D}\right)$, in Fig. $8 \mathrm{~b}$, we observe that the magnitude of $C_{H}\left(=C_{E}\right)$ decreases with increasing wind speed. At larger wind speeds, it becomes almost constant and there is very little scatter at these wind speeds, whereas large scatter can be seen in the lower wind speed regime. Bradley et al. (1991) pointed out that the large scatter in the measured values of $C_{H}$ can arise because of the very low heat fluxes, about the order of what can be obtained at the limit of resolution of the turbulence measurements. However, it is worth mentioning that the estimates of the air-sea exchange coefficients are strongly dependent on the bulk scheme adopted and its dependence on stability. Table 2 compares the estimates of the air-sea exchange coefficients of sensible heat $\left(C_{H}\right)$ and water vapour $\left(C_{E}\right)$ obtained in the present study with those obtained by other investigators.

Using the bulk transfer coefficients already obtained, we now attempt to study the variation of these coefficients for neutral stratification. The expression for neutral stability transfer coefficient (shown in Eq. 4, Sect. 3) is hypothetical, since neutral stability implies zero heat flux at the surface and a nonexistent potential temperature gradient (Bradley et al., 1991). In the revised bulk scheme adopted for the present analysis, the neutral stability transfer coefficients for heat and moisture $\left(C_{H N}=C_{E N}\right)$ are taken as constants with a prescribed value of $1.15 \times 10^{-3}$ (Smith, 1988). Now we study the variation of neutral drag coefficient $\left(C_{D N}\right)$ with respect to the wind speed over the Indian Ocean. We understand from Fig. 8c that for the larger wind speed regime $\left(>4 \mathrm{~ms}^{-1}\right)$, there is a significant increase in the magnitudes of $C_{D N}$ (from 0.85 to $1.5 \times 10^{-3}$, which implies that with increasing wind speed, the sea surface roughness also increases). The increase in the magnitude of $C_{D N}$ at low wind speeds can again be attributed to the viscous term defined in Eq. (11) (Sect. 3). Based on the scatter plot of $C_{D N}$ vs. wind speed, we have derived an empirical relation between our estimates of $C_{D N}$ with the observed values of wind speeds. The equation representing the best fit is also shown in the figure, to arrive at the following empirical relationship for $C_{D N}$ :

$$
\begin{aligned}
& C_{D N}=[(0.8366 \pm 0.0423) \\
& \left.\quad+(0.0436 \pm 0.0005) \times U_{10}\right] \times 10^{-3} .
\end{aligned}
$$

DeCosmo (1991) gives a comparison of the various regression estimates of drag coefficients at $10-\mathrm{m}$ height. A few $C_{D N}$ regression equations with the respective range of wind speeds reported by DeCosmo (1991), Garratt (1977) and the present study are detailed in Table 2 . These equations, derived empirically, spread over a wide range of wind speeds. Equation (15) gives the wind speed dependence of drag coefficient for neutral stratification over a wind speed range, $1-14 \mathrm{~ms}^{-1}$. Stull (1988) gives the average magnitudes of drag coefficients over different continents (see Table 7-2, pp. 264). Several studies suggested that the variance in the drag coefficient estimates may be explained primarily by an additional dependence of $C_{D}$ on sea state, but the mathematical formulation which best describes this relationship for non-equilibrium conditions is not readily agreed upon by many investigators. To summarize the behaviour of air-sea exchange parameters over the tropical Indian Ocean and Central Arabian Sea during the INDOEX, IFP-99 campaign and their wind speed dependence, the statistical estimates and the errors in the estimates are given in Table 3.

\section{Summary}

In the present study, the wind speed dependence of air-sea exchange coefficients over the Indian Ocean during the INDOEX, IFP-99 campaign is reported. The magnitude of the exchange coefficient depends on many factors, including the wind speed, fetch and wave age, stability, the scheme adopted for the estimation of these coefficients, etc. In this study, however, we have attempted to show only the wind speed dependence of the air-sea exchange parameters. The key features revealed from the study can be summarized as follows:

- The drag coefficient estimates for neutral stratification increases at low wind speeds, typically in the range 1$4 \mathrm{~ms}^{-1}$.

- For larger winds $\left(>4 \mathrm{~ms}^{-1}\right)$, there is a significant increase in the magnitude of the neutral drag coefficient, and the coefficients show an increasing trend with increasing wind speed.

- In contrast to the variation of drag coefficient, the exchange coefficients for heat and moisture $\left(C_{H}\right.$ and $\left.C_{E}\right)$ 
Table 2. Review on comparison of estimates in air-sea exchange coefficients $\left(C_{H}\right.$ and $\left.C_{E}\right)$ and regression of drag coefficient for neutral stratification $\left(C_{D N}\right)$ based on wind speed at $10-\mathrm{m}$

\begin{tabular}{|c|c|c|c|c|c|}
\hline Investigators & $\begin{array}{l}\text { WS } \\
\text { range } \\
\left(\mathrm{ms}^{-1}\right)\end{array}$ & $\begin{array}{l}C_{H N} \\
\left(\times 10^{-3}\right)\end{array}$ & $\begin{array}{l}C_{E N} \\
\left(\times 10^{-3}\right)\end{array}$ & $\begin{array}{l}10^{-3} \\
\text { Regression } \\
\text { Equation }\end{array}$ & Remarks/Reference \\
\hline Priestly (1951) & $\begin{array}{l}2.5-12 \\
\text { strong }\end{array}$ & - & - & $\begin{array}{l}1.25 \\
2.6\end{array}$ & (Aust. J. Sci. Res., A4, 1951) \\
\hline Wilson (1960) & $\begin{array}{l}\sim 1-5 \\
9-20\end{array}$ & - & - & $\begin{array}{l}1.42 \\
2.37\end{array}$ & (J. Geophy. Res. 65, 1960) \\
\hline Deacon and Webb (1962) & $2.5-13$ & - & 1.0 to 1.6 & $1.0+0.07 \mathrm{U}_{10 N}$ & (The Sea, Vol. 1, Interscience, 1962) \\
\hline Robinson (1966) & $\begin{array}{l}3-8.5 \\
2.5-14\end{array}$ & - & - & $\begin{array}{l}1.8 \\
1.48\end{array}$ & (Quart. J. Roy. Met. Soc. 62, 1966) \\
\hline Wu (1969) & $\begin{array}{l}3-15 \\
15-21\end{array}$ & - & - & $\begin{array}{l}0.5\left(U_{10 N}\right)^{0.5} \\
2.5\end{array}$ & (J. Geophy. Res. 74, 1969) \\
\hline Hasse (1970) & $3-11$ & 1.0 & 1.0 & $1.21 \pm 0.24$ & $\begin{array}{l}\text { Buoy data;(Oregon State } \\
\text { University Tech. Rep.188) }\end{array}$ \\
\hline Hidy (1972) & $2-10$ & - & - & 1.5 & (Bull. Amer. Met. Soc. 53, 1972) \\
\hline Smith and Banke (1975) & $2.5-21$ & - & - & $0.63+0.066 U_{10 N}$ & $\begin{array}{l}\text { Sable Island, Surf zone, Based on } \\
\text { Mast platform; } \\
\text { (Quart.J.Roy.Met.Soc. 115, 1975) }\end{array}$ \\
\hline Kondo (1975) & $3-16$ & - & - & $1.2+0.025 U_{10 N}$ & $\begin{array}{l}\text { Tower data, } \\
\text { (Bound.Layer.Meteor. 9, 1975) }\end{array}$ \\
\hline Garratt (1977) & $3-21$ & - & - & $0.75+0.067 U_{10 N}$ & $\begin{array}{l}\text { Compilation of several previously } \\
\text { published data sets }\end{array}$ \\
\hline
\end{tabular}

do not show any significant variation with increasing wind speed in the wind speed range $1-14 \mathrm{~ms}^{-1}$. An average value of the exchange coefficients are:

$$
-C_{H N}\left(=C_{E N}\right)=1.11 \pm 0.06 \text {. }
$$

- Estimates of the drag coefficient for neutral stratification over the Indian Ocean using the present scheme, provide the following regression equation for $C_{D N}$ with wind speed:

$$
-C_{D N}=\left[0.8366+0.0436 \times U_{10}\right] \times 10^{-3} .
$$

- Except for low winds $\left(<3 \mathrm{~ms}^{-1}\right)$, the velocity roughness length $\left(z_{0}\right)$ increases with increasing wind speed. In contrast, the roughness length for temperature and humidity $\left(z_{0 t}\right.$ and $\left.z_{0 q}\right)$ show a decreasing trend with increasing wind speed $\left(>3 \mathrm{~ms}^{-1}\right)$.

\section{Concluding remarks}

The INDOEX, IFP-99 campaign provided an opportunity to study the structure and characteristics of MABL over the Indian Ocean. In the present article, some of the features of air-sea interaction over the Indian Ocean are addressed. Airsea exchange parameters of water vapor, heat and momentum are important inputs for mesoscale and GCM modeling. These are particularly lacking over the tropical oceans. Various schemes were published from time to time for the computation of bulk transfer coefficients. There are several studies that report MABL characteristics over oceans; such studies over the tropical Indian Ocean region, however, are few. In the present study, an attempt is being made to show the behaviour of the surface roughness length and air-sea exchange coefficients from data collected over a wide region of the tropical Indian Ocean during INDOEX, IFP-99 campaign. Webster and Lukas (1992) emphasized that "the variation of fluxes between the ocean and the atmosphere is very sensitive to the choice of parameterization, especially in low wind regimes." Miller et al. (1992), who found dramatic improvements in simulated tropical phenomena by strengthening the air-sea coupling in the light wind regime, verifies this fact. In low wind speed regimes it is necessary to account for buoyancy effects on the turbulent transport, an aspect that is dealt with in the standard stability dependent bulk scheme adopted by Smith (1988), which shows a good performance in the tropics (Bradley et al., 1991). Estimates of bulk transfer coefficients and roughness lengths for velocity, tempera- 
Table 2. continued....

\begin{tabular}{|c|c|c|c|c|c|}
\hline Investigators & $\begin{array}{l}\text { WS } \\
\text { range } \\
\left(\mathrm{ms}^{-1}\right)\end{array}$ & $\begin{array}{l}C_{H N} \\
\left(\times 10^{-3}\right)\end{array}$ & $\begin{array}{l}C_{E N} \\
\left(\times 10^{-3}\right)\end{array}$ & $\begin{array}{l}10^{-3} \\
\text { Regression } \\
\text { Equation }\end{array}$ & Remarks/Reference \\
\hline Pond et al. (1971) & $4-8$ & 1.0 & $\begin{array}{l}1.23 \pm 0.17 \\
1.25 \pm 0.25\end{array}$ & $1.5 \times 10^{-3}$ & $\begin{array}{l}\text { Large buoy data; Comparison of } \\
\text { eddy correlation and inertial dissi- } \\
\text { pation method. (J.Atmos.Sci.28, 1971) }\end{array}$ \\
\hline $\begin{array}{l}\text { Large and Pond } \\
(1981,1982)\end{array}$ & $10-25$ & - & - & $0.49+0.065 U_{10 N}$ & Compilation of ocean measurements \\
\hline Donelan (1982) & $4-16$ & - & - & $0.35+0.142 U_{10 N}$ & Lake Ontario, $10 \mathrm{~m}$ \\
\hline Geernaert et al. (1986) & $5-22$ & - & - & $0.40+0.117 U_{10 N}$ & North Sea, $15 \mathrm{~m}$ \\
\hline Geernaert et al. (1987) & $5-25$ & - & - & $0.577+0.085 U_{10 N}$ & North Sea, $30 \mathrm{~m}$ \\
\hline Smith (1988) & $6-22$ & 1.0 & 1.2 & $0.81+0.049 U_{10 N}$ & North Atlantic, Deep water \\
\hline Bradley et al. (1991) & $4-6$ & 1.03 & 0.89 & 1.16 & $\begin{array}{l}\text { Micrometeorological measurements } \\
\text { carried onboard R/V Franklin over } \\
\text { the western equatorial pacific ocean }\end{array}$ \\
\hline Large et al. (1994) & $1-25$ & $\begin{array}{l}32.7\left(C_{D}\right)^{1 / 2} \\
\text { unstable } \\
18.0\left(C_{D}\right)^{1 / 2} \\
\text { stable }\end{array}$ & $\left(2.7 / U_{10 N}+0.142\right.$ & $\begin{array}{l}34.6\left(C_{D}\right)^{1 / 2} \\
+0.0764 U_{10 N}\end{array}$ & $\begin{array}{l}\text { (Reviews of Geophysics.) } \\
32 / 4,1994\end{array}$ \\
\hline DeCosmo et al. (1996) & $5-23$ & 1.14 & 1.12 & $0.27+0.116 U_{10 N}$ & HEXOS results \\
\hline $\begin{array}{l}\text { Enriquez and } \\
\text { Friehe (1997) }\end{array}$ & $2-17$ & $1.05 \pm 0.39$ & - & $0.509+0.065 U_{10 N}$ & $\begin{array}{l}\text { Aircraft measurements during } \\
\text { SMILE, (J.Geophy.Res. 102, 1997) }\end{array}$ \\
\hline $\begin{array}{l}\text { Enriquez and } \\
\text { Friehe (1997) }\end{array}$ & $2-17$ & - & - & $0.6492+0.0571 U_{10 N}$ & $\begin{array}{l}\text { Aircraft measurements during } \\
\text { CODE, (J.Geophy.Res. 102, 1997) }\end{array}$ \\
\hline $\begin{array}{l}\text { Rutgersson et al. } \\
\text { (2001) }\end{array}$ & $2-15$ & $1.0 \pm 0.3$ & $1.2 \pm 0.2$ & - & $\begin{array}{l}\text { Baltic Sea measurements, } \\
\text { (Bound.Layer.Meteorol. 99, 2001) }\end{array}$ \\
\hline $\begin{array}{l}\text { Subrahamanyam and } \\
\text { Radhika, (Present Study) }\end{array}$ & $1-14$ & $1.11 \pm 0.06$ & $1.11 \pm 0.06$ & $0.8366+0.0436 U_{10 N}$ & $\begin{array}{l}\text { Western Tropical Indian Ocean } \\
\text { during INDOEX, IFP-99 }\end{array}$ \\
\hline
\end{tabular}

Table 3. Statistical estimates of parameters and their wind speed dependence during INDOEX, IFP-99

\begin{tabular}{ccccccc}
\hline Parameter & Minimum & Maximum & Mean & $\begin{array}{c}\text { Std. } \\
\text { Deviation }\end{array}$ & $\begin{array}{c}\text { Std. } \\
\text { Error }\end{array}$ & $\begin{array}{c}\text { Corr.Coeff. } \\
\text { w.r.t. WS }\end{array}$ \\
\hline$z_{0}$ & $2.619 \mathrm{e}-5$ & $2.7124 \mathrm{e}-4$ & $7.94827 \mathrm{e}-5$ & $5.3524 \mathrm{e}-5$ & $3.2101 \mathrm{e}-6$ & 0.8671 \\
$z_{0 t}=\left(z_{0 q}\right)$ & $1.768 \mathrm{e}-5$ & $1.989 \mathrm{e}-4$ & $1.00 \mathrm{e}-4$ & $5.38 \mathrm{e}-5$ & $3.23 \mathrm{e}-6$ & 0.9209 \\
$C_{D N}$ & 0.97 & 1.45 & 1.13108 & 0.12152 & 0.00729 & 0.95317 \\
$C_{H N}=\left(C_{H N}\right)$ & 1.03 & 1.28 & 1.11219 & 0.06052 & 0.00362 & 0.95493 \\
\hline
\end{tabular}

ture and humidity over the Indian Ocean are obtained using a method based on the bulk algorithm suggested by Smith (1988). A modification is suggested in this work to the bulk algorithm suggested by Smith (1988) by way of iteratively computing $u *, z_{0}, z_{0 t}$ and $z_{0 q}$. It has effectively improved the accuracy of the estimates of the exchange coefficients, in turn, providing a fairly reliable estimate of the fluxes.
Our estimates of the drag coefficients, particularly over the meridional tracks, could have an inherent error since it is cross-equatorial, where one can expect large gradients. The general assumption of a homogeneous boundary layer, in this case, may not be valid. Relatively large variability in the meridional track estimates against zonal track estimates, particularly in consonance with large SST and wind speed gra- 
dients, evident in this study, point to this fact. Hence, to that extent there is a limitation in the accuracy of the estimates of the parameters along the meridional track reported in this study.

Although there is a general agreement among investigators that the wind drag coefficient increases with increasing wind speed over the ocean, there is also a strong view against the empirically determined coefficients of the simple linear formula, which quantifies this relationship. This can be attributed to the inefficient calibration and other errors due to sensor deployment caused by flow distortion, violation of the assumptions of steady state and of isotropic turbulence and the underlying physics of the scheme adopted for estimating the bulk transfer coefficients. Concerted effort, by way of both research and field experiments, are necessary to further strengthen our understanding of the boundary layer parameterization and the bulk schemes over the tropical oceans.

Acknowledgements. We acknowledge with thanks the help rendered by Dr. K Sen Gupta, Former-Head, Boundary Layer Physics (BLP) Branch, Space Physics Laboratory, Vikram Sarabhai Space Centre, Thiruvananthapuram for initiating the BLP component of the INDOEX programme. We are grateful to Dr. A.P. Mitra, Chairman, National Steering Committee, Shri G. Viswanathan, Program Director, INDOEX-India Program, Dr. N. Bahulayan, Chief Scientist onboard ORV Sagar Kanya and all the members of the Indian component of INDOEX program for their strenuous efforts for making the Indian component of the campaign a great success. Thanks are also due to the anonymous reviewers for their critical appraisal of the manuscript, which in turn, improved the contents of the paper to a great extent. One of the authors, Subrahamanyam, who was a participant in the INDOEX, IFP-99 campaign, is thankful to the Indian Space Research Organization (ISRO) for providing the Research Fellowship for carrying out this research.

Topical Editor N. Pinard'e thanks two referees for their help in evaluating this paper.

\section{References}

Blanc, T. V.: Accuracy of Bulk-Method-Determined Flux, Stability, and Sea Surface Roughness, J. Geophys. Res., 92, 3867-3876, 1987.

Blanc, T. V.: Variation of bulk-derived surface flux, stability and roughness results due to the use of different transfer coefficient schemes, J. Phys. Ocean., 15, 650-659, 1985.

Bradley, E. F., Coppin, P. A., and Godfrey, J. S.: Measurements of sensible and latent heat flux in the western equatorial Pacific Ocean, J. Geophys. Res., 96, 3 375-3 389, 1991.

Businger, J. A., Wyngaard, J. C., Izumi, Y., and Badgley, E. F.: Flux profile relationships in the atmospheric surface layer, J. Atmos. Sci., 28, 181-189, 1971.

Byun, D. W.: On the analytical solutions of flux-profile relationships for the atmospheric surface layer, J. Applied Meteo., 29, 652-657, 1990.

Charnock, H.: Wind stress on the water surface, Q. J. R. Meteo. Soc., 81, 639-640, 1955.

Deacon, E. L. and Webb, E. K.: Interchange of properties between sea and air, The Sea, Vol. 1, Interscience, 43-87, 1962.

Dyer, A. J.: A review of flux-profile relationships, Boundary Layer Meteorology, 7, 363-372, 1974.
DeCosmo, J.: Air-Sea Exchange Of Momentum, Heat And Water Vapor Over Whitecap Sea States, Ph.D. Dissertation, University of Washington, Seattle, WA 98165, 212 pp., 1991.

DeCosmo, J., Kastaros, K. V., Smith, S. D., Anderson, R. J., Oost, W. J., Bumke, K., and Chadwick, H.: Air-Sea Exchange of water vapor and sensible heat: The Humidity Exchange Over the Sea (HEXOS) results, J. Geophys. Res., 101, 12 001-12 016, 1996.

Donelan, M.: The dependence of the aerodynamic drag coefficient on wave parameters, First International Conference on Meteorology and Air-Sea Interaction of the Coastal Zone, American Meteorological Society, Boston, MA, pp. 381-287, 1982.

Enriquez, A.G. and Friehe: C.A., Bulk parameterization of momentum, heat, and moisture fluxes over a coastal upwelling area, J. Geophys. Res., 102, 5781-5798, 1997.

Fairall, C. W., Bradley, E. F., Rogers, D. P., Edson, J. B., and Young, G. S.: Bulk parameterization of air-sea fluxes for Tropical Oceans and Global Atmosphere Coupled Ocean-Atmosphere Response Experiment, J. Geophys. Res., 101, 3 747-3 764, 1996.

Friehe, C. A. and Schmidt, K. F., Parameterization of air-sea interface fluxes of sensible heat and moisture by the bulk aerodynamic formulas, J. Phys. Ocean., 6, 801-809, 1976.

Garratt, J. R.: Review of drag coefficients over oceans and continents, Monthly Weather Review, 105, 914-929, 1977.

Garratt, J. R.: The Atmospheric Boundary Layer, Cambridge University Press, Cambridge, 316 pp., 1992.

Geernaert, G. L., Davidson, K. L., Larsen, S. E., and Mikkelsen, T.: Wind stress measurements during the Tower Ocean Wave and Radar Dependence Experiment, J. Geophys. Res., 93, 1391313 923, 1988.

Geernaert, G. L., Larsen, S. E., and Hansen, F.: Measurements of the wind stress, heat flux, and turbulence intensity during storm conditions over the North Sea, J. Geophys. Res., 92, $13127-$ 13 139, 1987.

Geernaert, G. L., Katsaros, K. B., and Richter, K.: Variation of the drag coefficient and its dependence on sea state, J. Geophys. Res., 91, 7 667-7 679, 1986.

Grachev, A. A. and Fairall, C. W.: Dependence of the MoninObukhov Stability Parameter on the Bulk Richardson Number over the Ocean, J. Applied Meteo., 36, 406-414, 1997.

Greenhut, G. and Khalsa, S. J. S.: Bulk transfer coefficients and dissipation derived fluxes in low wind speed conditions over the western equatorial Pacific Ocean, J. Geophys. Res., 100, 857863, 1995.

Hasse, L.: On the determination of vertical transports of momentum and heat in the atmospheric boundary layer at sea, Tech. Rep. 188, Dept. of Oceanography, Oregon State University, 1970.

Hicks, B. B.: Propeller anemometers as sensors of atmospheric turbulence, Boundary Layer Meteorology, 3, 214-228, 1972.

Hidy, G. M.: A view of recent air-sea interaction research, Bulletin of American Meteorological Society, 53, 1083-1102, 1972.

Kondo, J.: Air-sea bulk transfer coefficients in diabatic conditions, Boundary Layer Meteorology, 9, 91-112, 1975.

Kraus, E. B. and Businger, J. A.: Atmosphere-Ocean Interactions, Second Edition, Oxford University Press, New York, 352 pp., 1994.

Large, W. G., McWilliams, J. C., and Doney, S. C., Ocean vertical mixing: A review and a model with a nonlocal boundary layer parameterization, Rev. Geophys., 32, 363-403, 1994.

Large, W. G. and Pond, S.: Open ocean momentum flux measurements in moderate to strong winds, J. Phys. Ocean., 11, 324-336, 1981.

Large, W. G. and Pond, S.: Sensible and latent heat flux measure- 
ments over the ocean, J. Phys. Ocean., 12, 464-482, 1982.

Lo, A. K-F.: The Direct Calculation of Fluxes and Profiles in the Marine Surface Layer Using Measurements from a Single Atmospheric Level, J. Applied Meteo., 32, 1893-1 900, 1993.

Madan, O. P., Mohanty, U. C., Paliwal, R. K., et al.: Meteorological Analysis during INDOEX, Intensive Field Phase - 1999, Volume - II: Wind Analysis and Trajectories, Centre for Atmospheric Sciences, IIT Delhi, Hauz Khas, New Delhi, 110016, 1999.

Malhi, Y.: The behaviour of the roughness length for temperature over heterogeneous surfaces, Q. J. R. Meteo. Soc., 122: 10951125, 1996.

Miller, M. J., Beljaars, A. C. M., and Palmer, T. N.: The sensitivity of the ECMWF model to the parameterization of evaporation from the tropical oceans, J. Climate, 5, 418-434, 1992.

Paulson, C.A.: The mathematical representation of wind speed and temperature profiles in the unstable atmospheric surface layer, J. Applied Meteo., 9, 857-861, 1970.

Pond, S., Phelps, G. T., Paquin, J. E., McBean, G., and Stewart, R. W.: Measurement of the turbulent fluxes of momentum, moisture and sensible heat over the oceans, J. Atmos. Sci., 28, 901-917, 1971.

Priestley, C. H. B.: A survey of the stress between the ocean and atmosphere, Australian J. Sci. Res., A4, 315-328, 1951.

Ramanathan, V., Crutzen, P. J., Althausen, D., Anderson, J., Andreae, M. O., Clarke, A. D., Collins, W. D., Coakley, J. A., Heymsfield, A. J., Holben, B., Jayaraman, A., Kiehl, J. T., Krishnamurti, T. N., Lelieveld, J., Mitra, A. P., Novakov, T., Orgon, J. A., Podgorny, I. A., Prospero, J. M., Priestly, K., Quinn, P. K., Rajeev, K., Rasch, P., Rupert, S., Sadourney, R., Satheesh, S. K., Sheridan, P., Shaw, G. E., and Valero, F. P. J: The Indian Ocean experiment: wide spread haze from south and Southeast Asia and its climate forcing, J. Geophys. Res., 106, 28 371-28 398, 2001.

Ramanathan, V., Coakley, J. A., Clarke, A., et al.: Indian Ocean Experiment (INDOEX); A Multi-agency proposal for Field Experiment in the Indian Ocean (C4 Publication No. 162, Scripps Institution of Oceanography, La Jolla, CA, 1996); also at (http://www.indoex.ucsd.edu), 1996.

Robinson, G. D.: Another look at some problems of the air-sea interface, Q. J. R. Meteo. Soc., 92, 451-465, 1966.

Roll, H. U.: Physics of the Marine Atmosphere, Academic Press, 426 pp., 1965.

Rutgersson, A., Smedman, A.-S., and Omstedt, A.: Measured and simulated latent and sensible heat fluxes at two marine sties in the Baltic sea, Boundary Layer Meteorology, 99, 53-84, 2001.

Said, F. and Druilhet: A., Experimental Study of the Atmospheric Marine Boundary Layer from in-situ aircraft measurements (TOSCANE-T CAMPAIGN): Variability of boundary conditions and Eddy flux parameterization, Boundary Layer Meteorology, 47, 277-293. 1991.

Smith, S. D.: Water vapor flux at the sea surface, Boundary Layer Meteorology, 47, 277-293, 1989.
Smith, S. D.: Wind stress and heat flux over the ocean in gale force winds, J. Phys. Ocean., 10, 709-726, 1980.

Smith, S. D., Fairall, C. W., Geernaert, G. L., and Hasse, L.: AirSea Fluxes: 25 Years of Progress, Boundary Layer Meteorology, 78, 247-290, 1996.

Smith, S. D.: Coefficients for Sea Surface Wind Stress, heat Flux, and Wind Profiles as a Function of Wind Speed and Temperature, J. Geophys. Res., 93, 15 467-15 472. 1988.

Smith, S. D. and Banke, E. G.: Variation of the sea surface drag coefficient with wind speed, Q. J. R. Meteo. Soc., 101, 665-673, 1975.

Stull, R. B.: An Introduction to Boundary Layer Meteorology, Kluwer Academic Publishers, P.O. Box 17, 3300 AA Dordrecht, The Netherlands, 666 pp., 1988.

Subrahamanyam, D. B. and Radhika, R.: Air-Sea Interface Fluxes over the Indian Ocean during INDOEX, IFP-99, J. Atmos.-Solar Terr. Phys., 64/3, 291-305, 2002.

Subrahamanyam, D. B., Radhika, R., Sen Gupta, K., Mandal, T. K.: Variability of Mixed Layer Heights over the Indian Ocean and Central Arabian Sea during INDOEX, IFP-99, Boundary Layer Meteorology, 107, 683-695, 2003.

Subrahamanyam, D. B., Radhika, R., Sen Gupta, K., Krishnan, P., Kunhikrishnan, P. K., and Ravindran, S.: Marine Atmospheric Boundary Layer (MABL) Studies over the Indian Ocean during INDOEX, IFP-99, SPL Scientific Report, Also available at: http: //www.geocities.com/subbu_dbs/INDOEX/report_ifp.pdf, 2002.

Subrahamanyam, D. B., Sen Gupta, K., Ravindran, S., and Krishnan, P.: Study of sea breeze and land breeze along the west coast of Indian sub-continent over the latitude range $15^{\circ} \mathrm{N}$ to $8^{\circ} \mathrm{N}$ during INDOEX, IFP-99 (SK-141) cruise, Current Science (Supplement), 80, 85-88, 2001a.

Subrahamanyam, D. B., Sen Gupta, K., Ravindran, S., Kunhikrishnan, P. K., Radhika, R., Ramana, M. V., and Krishnan, P.: Variation of Marine Atmospheric Boundary Layer Parameters in the Latitude Range $15^{\circ} \mathrm{N}$ to $20^{\circ} \mathrm{S}$ and Longitude Range $63^{\circ} \mathrm{E}$ to $77^{\circ}$ E During INDOEX, IFP-99, Proceedings of the Symposium TROPMET 2000 on Ocean and Atmosphere, IMS (Cochin Chapter), CUSAT, Cochin - 682 016, Kerala, India, 410-414 pp., $2001 b$.

Troen, I. B. and Mahrt, L.: A simple model of the atmospheric boundary layer: sensitivity to surface evaporation, Boundary Layer Meteorology, 37, 129-148, 1986.

Webster, P. J. and Lukas, R.: TOGA COARE: The Coupled OceanAtmosphere Response Experiment, Bull. Amer. Meteo. Soc., 73, 1377-1 416, 1992.

Wilson, B. W.: Note on surface wind stress over water at low and high wind speeds, J. Geophys. Res., 65, 3377-3382, 1960.

$\mathrm{Wu}$, J.: The sea surface is aerodynamically rough even under light winds, Boundary Layer Meteorology, 69, 149-158, 1994.

$\mathrm{Wu}, \mathrm{J}$.: Wind stress and surface roughness at air-sea interface, J. Geophys. Res., 74, 444-455, 1969. 